\title{
Effects of cholinergic brain injections on mouse killing or carrying by rats*
}

\author{
DANIEL J. LONOWSKI, ROBERT A. LEVITT, and SCOTT D. LARSON \\ Southern Illinois Lniversity at Carbondale. Carbondale. Illinois 62901
}

\begin{abstract}
Some rats will consistently kill a mouse placed in their cage. others will simply carry the mouse around th: cage (without killing). While about $50 \%$ of the rats show neither behavior. This experiment investigated the effect of chemical brain stimulation with a cholinergic or anticholinergic drug on mouse killing and mouse carrying by rats. Carbachol significantly inhibited both killing and carrying. while atropine had no effect on the behaviors. These data are inconsistent with previous studies implicating cholinergic mechanisms in the facilitation of mouse killing. The implications of this study are discussed.
\end{abstract}

Acts of aggression among mammalian organisms are highly complex and diverse phenomena. Indeed, the stimulus conditions that will elicit aggressive behavior and the exact forms the response will assume are quite varied. Mouse killing in rats is a type of predatory aggression which is both stereotyped and stimulus specific. The behavior is typified by vigorous and repeated bites directed at the cervical spine of a mouse (Karli, 1956). Mouse killing is a stable behavior, and may be observed over several months (Karli. Vergnes, \& Didiergeorges. 1969). Furthermore. mouse killers will not kill rat pups matched for size and shape to resemble adult mice (Myer \& White. 1965).

Some rats, however. do not engage in mouse killing. Lpon close observation, many of these rats may be observed to pick up a mouse by the skin of the back and carry it around the cage (Lonowski, Levitt, \& Larson, 1973). This behavior. mouse carrying. appears to be as consistent and dynamic in its own right as mouse killing. Topographically, the behavior is similar to an attack directed at a mouse, but lacks the bite which characterizes mouse killers.

In recent years, the neurological parameters of mouse killing have been investigated. Electrical stimulation of the lateral hypothalamus (LH) in rats can both elicit (King \& Hoebel. 1968) and facilitate mouse killing (Karli. Vergnes, \& Didiergeorges, 1969).

However, two forms of aggression may be elicited by electrical stimulation to the LH, affective attack and quiet biting attack (Panksepp. 1971). In affective attack, rats will attempt to escape the electrical brain stimulation (EBS), will not eat their prey, and appear to be generally aroused. In quiet biting attack. rats do not attempt to escape the EBS, will eat their prey, and engage in mouse killing in the absence of generalized arousal patterns. Quiet biting attack. therefore. appears to be more similar to natural predation, whereas affective attack may involve a nonspecific activation of

*Supported by NIMH Research Grant MH-14381 and by the Office of Research and Projects of Southern Illinois Lniversity at Carbondale. killing behavior comparable to irritable aggression (Moyer, 1968).

Chemical stimulation of the rat brain provided further clues as to the neurobiochemical basis of predatory aggression. Smith, King, and Hoebel (1970) reported that central injections of carbachol (a cholinergic drug) into the $\mathrm{LH}$ elicited mouse killing in nonkilling rats. Furthermore, atropine in these sites inhibited mouse killing by killer rats. Bandler (1969, 1970, 1971a, b). however, using lower drug doses, reported a facilitation of killing with carbachol in the LH of killer rats but failed to replicate the conversion of nonkiller rats to killers. Carbachol injections were also found effective in facilitation of killing when placed in the medial thalamus and midbrain regions. Atropine in the LH did not inhibit mouse killing, but did so when placed in the thalamus or midbrain.

These findings were offered as evidence for a cholinoceptive system in the rat brain which underlies predatory aggression. This neural substrate was assumed to be activated by central injections of cholinergic drugs and deactivated by anticholinergic drugs.

In each of these previous studies. relatively large amounts of drugs were injected into the brain. Smith, King, and Hoebel used bilateral doses of $50 \pm 25 \mu \mathrm{g}$ of carbachol and $20 \pm 10 \mu \mathrm{g}$ atropine. Bandler used an average of $7.0 \mu \mathrm{g}$ of carbachol and $15 \mu \mathrm{g}$ of atropine.

Subsequent to stimulation with carbachol, Smith, King, and Hoebel reported that the rats were active, with evidence of parasympathetic arousal. Bandler, too, described the loss of several animals as a result of carbachol-induced seizures. Thus, accompanying a modification of mouse killing behavior in each study, there was evidence of disruptive nonspecific behaviors.

It is commonly recognized that any selective demonstration of drug action should be devoid of nonspecific behavioral effects. Furthermore, and perhaps more importantly, the amount of drug introduced into the brain should be as moderate as possible. This is especially true when making inferences concerning synaptic function and neural systems underlying specific 
forms of behavior (predatory aggression).

The present experiment was performed with the above concerns in mind. Lower doses of test drugs were employed. Drug injections were directed at the anterior-lateral hypothalamus in order to conform to previous studies. In addition, an equal number of chemical injections were delivered into the lateral septal nucleus ( $\mathrm{SN})$. This additional injection site was chosen because of the cholinergic sensitivity of this area in another response system (thirst: Levitt. 1971).

Rats chosen for study by chemical brain stimulation were of four classes: male mouse killers, female mouse killers. male mouse carriers, and female mouse carriers. Thus, drug effects on both killing and carrying, as well as sex differences, could be studied. It was hoped that some understanding of the relationship of the carrying response to killing might be achieved by comparing drug and sex influences on them.

\section{METHOD}

\section{Subjects}

Fifty male and 48 female adult rats of the Long-Evans strain were used as experimental Ss. Each animal weighed between 250 and $350 \mathrm{~g}$ at the start of the experiment. Ss were housed individually with food and water available ad lib.

Several hundred male and female adult albino mice were used as test stimuli. All mice were housed in groups of six with free access to food and water.

\section{Behavioral Screening}

A behavioral classification of mouse killer or carrier was made in the following manner: A rat was taken from its cage, held gently in the E's hand for $10 \mathrm{sec}$, then returned to its home cage. This procedure was considered necessary, since later chemical brain stimulation tests required the handling of Ss prior to behavioral observation. During the handling of each rat by the $E$. food and water were removed from the cage. In this way, any interactions between eating and drinking and the presentation of a mouse during this phase of testing could be reduced. Pilot data from this laboratory has shown that the above procedure has no observable effect on the integrity of natural mouse killing and carrying.

Once the rat had been returned to its home cage, and after a 5 -min interval, used here to simulate the 5 -min interval required for carbachol and atropine drug onsets in later testing, a naive albino mouse was placed in the rat cage and relevant responses were recorded. The behavioral screening test continued for $15 \mathrm{~min}$ during which time the behaviors of the rats were observed. The latencies to kill were recorded for killers. and the latencies to the first mouse carry were recorded for carriers. At the conclusion of the $15-\mathrm{min}$ test period. the mouse (whether dead or alive) was taken from the test cage and food and water were restored. A measurement of water intake, but not food intake. for a $1 \cdot h$ period was then initiated. In this way. mouse killing, mouse carrying, and water consumption were studied in the absence of any direct interaction which could have occurred if a mouse, food, and water were present in the home cage at the same time. This procedure was followed throughout all phases of testing.

Behavioral screening as specified above was conducted on 2 successive test days until four groups of animals, with $12 \mathrm{Ss}$ assigned to each group, were obtained. These groups were then designated as male killers. male carriers, female killers. and female carriers. Approximately $25 \%$ of the tested rats were killers. $25 \%$ carriers. and $50 \%$ exhibited neither behavior. Once classifications had been made. each of the animals was surgically implanted with chemical implants.

\section{Surgery}

Each behaviorally classified rat was stereotaxically implanted with a 23-ga cannula for delivering chemicals into localized areas of the brain. All surgical procedures were conducted under sodium pentobarbital anesthesia. The guide shafts were aimed at two neural structures: the lateral septal nucleus $(\mathrm{SN} ; 1.8 \mathrm{~mm}$ anterior to bregma. $0.75 \mathrm{~mm}$ lateral to the midsaggital sinus at a depth of $4 \mathrm{~mm}$ below the top of the skull). and the lateral hypothalamic area $(\mathrm{LH}: 0.6 \mathrm{~mm}$ posterior to bregma. $1.5 \mathrm{~mm}$ lateral to the midsaggital sinus at a depth of $8.0 \mathrm{~mm}$ ). A minimum of $72 \mathrm{~h}$ was allowed for each animal to recover from surgery. Six animals of each separate group (male killers. female killers, male carriers. female carriers) were implanted in the LH and six in the $\mathrm{SN}$.

\section{Postsurgical Behavioral Testing}

\section{Control Screening}

Following surgery by 7 days. each animal was retested in a manner similar to that described in the behavioral screening section. Retests of this kind were made to ascertain the effects, if any. from trauma experienced during surgery which might have altered behavioral classification. A nimals failing to achieve response stability were eliminated from subsequent tests. Only 2 animals out of the 48 had to be replaced.

\section{Chemical Brain Stimulation}

One day following the postsurgical control screening. chemical brain stimulation was begun. The general procedure was as follows:

All rats were taken from their home cages and held gently by the E. chemically stimulated using a Hamilton microliter sy ringe with attached 30-ga needle, then placed back in the home cage where food and water had been removed. Since previous data showed that the average response latency to carbachol is about $5 \mathrm{~min}$ for another behavioral system (Levitt. 1971). each rat remained in its cage alone for an additional $5 \mathrm{~min}$ before the presentation of an albino mouse into its cage. Once the mouse was presented to the rat. a record of its killing or carrying behavior was made during a 15 -min period. In a subsequent $1-\mathrm{h}$ period. after the mouse was removed from the cage. water intake was measured.

Each of the three chemicals. carbachol. atropine sulfate. and isotonic saline, was injected once in a counterbalanced order into a specified neural site (either LH or SN). A 3-day interval separated each of the three drug treatments. The drugs used for chemical brain stimulation were carbachol (carbamyl choline chloride), atropine sulfate. and isotonic saline $(0.9)$. Previous studies (Levitt \& Fisher. 1966; Levitt \& Krikstone. 1968; Krikstone \& Levitt. 1970; Lonowski \& Levitt. 1973) in this laboratory have established $2.0 \mu \mathrm{g}$ of carbachol and $2.5 \mu \mathrm{g}$ of atropine as efficient doses for the elicitation of drinking. and 0.9 isotonic saline as an adequate control drug. Each drug was injected into the brain dissolved in $1.0 \mu \mathrm{l}$ of sterile isotonic saline using a Hamilton microliter syringe with an attached 30 -ga needle which could be positioned through the implanted guide shaft to an appropriate depth.

\section{Final Control Screening}

Subsequent to chemical brain stimulation with the three test drugs, each rat was once again tested for killing or carrying and water intake. A determination of the long-range effects of brain stimulation on previously stable responses could thus be made. 
The procedure followed for this test was identical to that outlined in the behavioral screening phase.

\section{Histology}

Following the general testing procedure, each of the 48 rats was sacrificed using an overdose of sodium pentobarbital; the animals were then perfused with normal saline and a $10 \%$ Formalin solution. Frozen brain sections were cut at 40 -micron intervals along the path of chemical delivery, stained with cresyl violet, and observed microscopically in order to ascertain the exact location of the implant placement.

\section{RESULTS}

\section{Mouse Killing}

An analysis of variance indicated that kill latencies were significantly affected by chemical brain stimulation $(F=17.32, \mathrm{df}=4 / 80, \mathrm{p}<.001)$ but not by the sex of the $\mathrm{S}$ or the structure stimulated. Post-ANOVA analysis by the Tukey test showed that carbachol increased the latency to kill above that found under the other chemicals or the control tests. In contrast, the latencies to kill under the other conditions were not different from each other. As there was no difference in the effect of the drugs on mouse killing as a function of the sex of the animal or the structure stimulated (Fig. 1), these data are collapsed across sex and structure in Fig. 2 .

Further information on the effect of carbachol on mouse killing should prove enlightening. Of the 24 killer rats injected with carbachol, 12 had assigned maximum latencies of $900 \mathrm{sec}$, whereas the other 12 did kill a mouse during the test. The 12 that did kill had an average latency of $309 \mathrm{sec}$, indicating an inhibitory effect even in those animals that did kill on this test.

Following each 15 -min kill test, each rat had a 60-min drinking test. No significant difference was found in water intake as a function of sex or implant location. However, one of the chemical treatments, carbachol, significantly increased water intake above that following each of the other treatments $(F=3.64$, df $=4 / 80$, $\mathrm{p}<.01$; validated by post-ANOVA Tukey tests). Considering all 24 killer rats, water intake following stimulation with carbachol averaged $4.0 \mathrm{ml}$, while

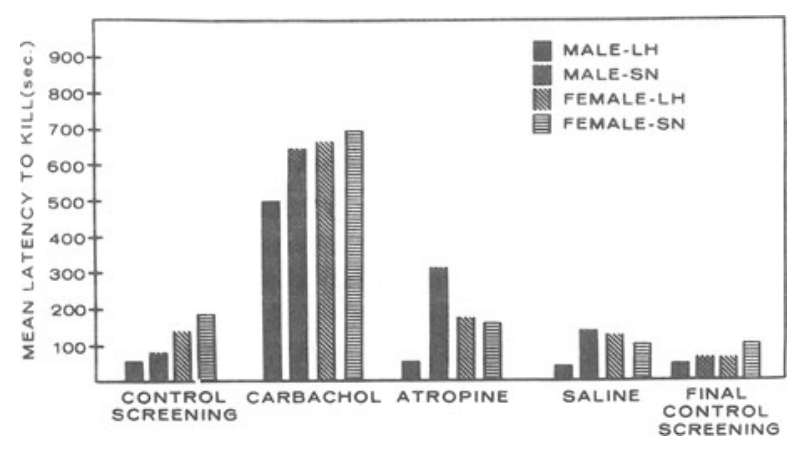

Fig. 1. Latency to kill as a function of gender and implant placement.

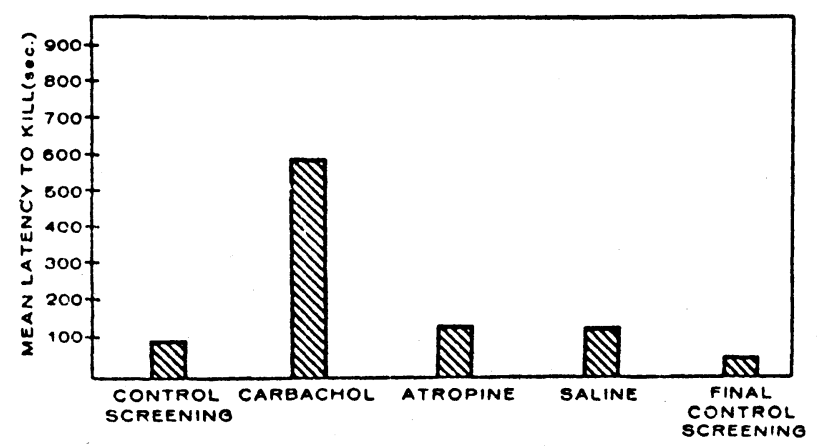

Fig. 2. The effects of chemical brain stimulation on latency to kill a mouse (scores collapsed across gender and implant placement).

average water intake on the control, atropine, and saline tests ranged between 1.0 and $2.0 \mathrm{ml}$. The 24 rats were then separated into two groups of drinkers and nondrinkers, by dividing the Ss into those that drank $3.0 \mathrm{ml}$ or more and those that drank less than $3.0 \mathrm{ml}$ following stimulation with carbachol. The drinkers averaged $6.5 \mathrm{ml}$ of water, while the nondrinkers averaged $0.5 \mathrm{ml}$.

It was thought that the inhibition of killing produced by carbachol might be related to the elicitation of another drive, thirst, by the drug. This was found not to be the case, since the latencies to kill in drinker and nondrinker rats were not significantly different. The average kill latency for drinkers was $590 \mathrm{sec}$, while that for nondrinkers was $550 \mathrm{sec}$.

This question was further investigated in a control experiment. Killer rats were tested with a mouse when water deprived for 12 or $24 \mathrm{~h}$. These animals immediately killed the mice. Therefore, the "thirst" produced by an injection of carbachol into the brain, or by deprivation of water, does not in itself inhibit mouse killing.

\section{Mouse Carrying}

An analysis of variance indicated that latency to carry was significantly affected by chemical brain stimulation $(F=11.83, \mathrm{df}=4 / 80, \mathrm{p}<.001)$, but, as in the case of mouse killing, not by the sex of the $S$ or the structure stimulated. These data are shown in Fig. 3 collapsed across sex and structure. Post-ANOVA analyses by the Tukey tests showed that latency to carry was increased by carbachol above that found on the other tests, which did not differ from each other.

Unlike the case with killers, water intake was not increased in carrier rats by carbachol. Therefore, an analysis of the relationship of drinking to carrying could not be undertaken.

\section{Duration of Effects}

An additional control experiment was performed on a 


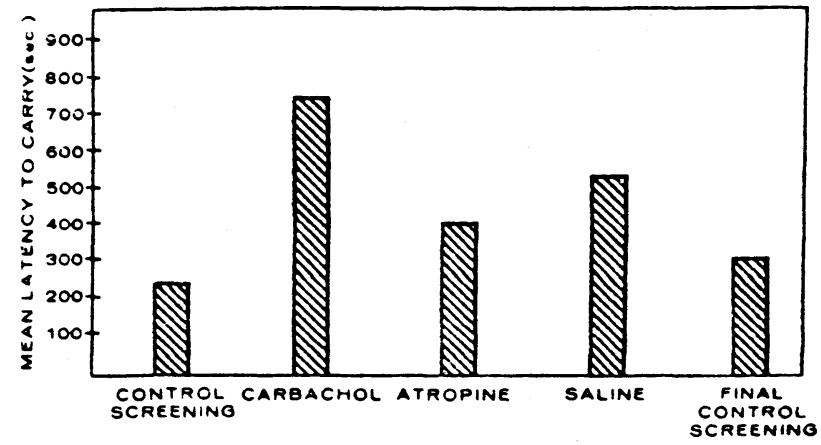

Fig. 3. The effects of chemical brain stimulation on latency to carry a mouse (scores collapsed across gender and implant placement).

new group of 32 rats to determine the duration of the inhibitory effects produced by carbachol. For this test, 17 mouse killers, 8 mouse carriers, and 7 rats that showed neither killing nor carrying behavior (nonkillers-noncarriers) were employed. Each rat was observed in the continual presence of a mouse for $24 \mathrm{~h}$ after the injection of carbachol into the lateral hypothalamus or until the rat displayed killing or carrying behavior.

Carbachol inhibited mouse killing in 9 of the 17 killer rats. The inhibition in these 9 rats lasted an average of $9 \mathrm{~h}$ (range: $21 \mathrm{~min}$ to the end of the 24-h observation period). Similarly, carbachol inhibited mouse carrying in 6 of the 8 carrier rats. The inhibition in all 6 rats lasted the full 24-h observation period. In no case did any of the 8 carrier rats or the 7 nonkiller-noncarrier rats kill a mouse during the 24 -h observation period. Three days after the carbachol injection, the killer and carrier rats were retested, and their previous killing or carrying behavior had returned by this time.

\section{Histology}

Histological examination of cresyl violet stained frozen sections showed the lateral hypothalamic stimulation sites to be located between the mammilothalamic tract and the optic tract, ventral to the fornix at the level of the ventral medial nucleus. The lateral septal stimulation sites were found in the dorsal medial area of the structure.

\section{DISCUSSION}

The most important finding of this study was that the central application of carbachol inhibited mouse killing by killer rats and mouse carrying by carrier rats. These effects were seen when carbachol was injected into either the lateral hypothalamus or the lateral septal nucleus of male or female rats. Atropine and isotonic saline injections had no effect on mouse killing or mouse carrying.

These results are particularly important in view of previous reports of cholinergic involvement in mouse killing behavior. Smith, King, and Hoebel (1970) reported that carbachol application to the lateral hypothalamus elicited mouse killing in nonkiller rats. Atropine delivered to the identical site inhibited mouse killing in killer rats. From their results. these investigators have suggested that the rat brain contains a cholinoceptive component of an innate system which underlies predatory aggression. Bandler (1969. 1970 , 1971a.b) failed to replicate this elicitation of mouse killing in nonkiller rats. However. carbachol was found to facilitate mouse killing in killer rats. Atropine injections were found to inhibit the carbachol facilitation of mouse killing. These findings were viewed by Bandler as evidence for a cholinergic substrate of predatory aggression.

The findings of this study do not conform to the results and conclusions of Smith, King, and Hoebel or of Bandler. Several methodological differences in these studies may have contributed to this fact. These discrepancies include: strain of rats tested, behavioral screening procedure, and availability of food and water during mouse tests. The most likely explanation. however, would seem to lie in the drug levels used in these studies.

Smith, King, and Hoebel reported using bilateral doses of $50 \pm 25 \mu \mathrm{g}$ of carbachol and $20 \pm 10 \mu \mathrm{g}$ of atropine. Bandler employed smaller doses of $7 \mu \mathrm{g}$ for carbachol and $15 \mu \mathrm{g}$ for atropine. In either case, but especially in the first study, these dosages were higher than in the current study and may have resulted in nonspecific behavioral effects. Smith and his associates reported that prior to killing, rats were highly active and exhibited piloerection and salivation. The kill latencies in these rats were also unusually long ( $45 \mathrm{~min}$ ) when compared to cholinergic activation of other response systems (Levitt, 1971). Bandler, too, reported the loss of experimental animals due to convulsions subsequent to carbachol brain stimulation. In view of these symptoms which may be a reflection of megative reinforcement or pain induction, the activation of mouse killing by carbachol would seem to conform more to irritable aggression (affective attack: Panksepp. 1971). In a similar fashion, large doses of atropine may have inhibited mouse killing by a general depressive effect (Bradley, 1968).

The drug doses selected for this study have been found to be effective in the elicitation and blockade of the cholinergic drinking phenomenon. They are low enough to decrease the possibility of nonspecific effects cited in prior studies. Since doses of carbachol were optimal for eliciting drinking, it is not surprising that water intake was elevated (but only in killer rats) following carbachol injections. There was, however, no relationship found between the production of thirst and the inhibition of mouse killing.

Although these data lead to a questioning of the mechanism responsible for the facilitation of killing produced by carbachol in previous studies, we have no ready explanation for the inhibition found in the current study. Since both killing and carrying were inhibited. carbachol may be suggested to have an inhibitory effect 
on a variety of behaviors (although. of course. drinking is facilitated). Whether these inhibitory effects result from a general inhibition and whether this inhibition is in any way cholinergically selective remains to be determined by future studies.

\section{REFERENCES}

Bandler. R. J.. Jr. Facilitation of aggressive behavior in the rat by direct cholinergic stimulation of the hypothalamus. Nature. 1969. 224. $1035-1036$

Bandler. R. J.. Jr. Cholinergic synapses in the lateral hypothalamus for the control of predatory aggression in the rat. Brain Research. 1970. 20. 409-424.

Bandler. R. J.. Jr. Direct chemical stimulation of the thalamus: Effects on aggressive behavior in the rat. Brain Research. 1971a. 26. 81-93.

Bandler. R. J.. Jr. Chemical stimulation of the rat midbrain and aggressive behavior. New Biology. 1971b. 229. 222-223.

Bradley. P. B. The effect of atropine and related drugs on EEG and behavior. Progress in Brain Research. 1968, 28, 3-10.

Karli. P. The Norway rat's killing response to the white mouse. Behaviour. 1956. 10.81-103.

Karli. P.. Vergnes. II.. \& Didiergeorges. F. Rat-mouse interspecific aggressive behavior and its manipulation by brain ablation and brain stimulation. In E. G. Sigg and S. Garattini (Eds.l. Biologr of aggressile beharior. Amsterdam: Excerpta Medica Foundation. 1969. Pp. 47-55.

King. II. B.. \& Hoebel. B. G. Killing elicited by brain stimulation in rats. Communications in Behavioral Biology. 1968. 2. 173-177.
Krikstone. B. J.. \& Levitt. R. A. Interactions between water deprivation and chemical brain stimulation. Journal of Comparative \& Physiological Psychology. 1970. 71. 334-340.

Levitt. R. A. Cholinergic substrate for drinking in the rat. Psichological Reports. 1971. 29. 431.448.

Levitt. R. A.. \& Fisher. A. E. Anticholinergic blockade of centrally induced thirst. Science. 1966. 154. 520-522.

Levitt. R. A.. \& Kriksione. B. J. Cortical spreading depression and thirst. Physiology \& Behavior. 1968. 3. 421-423.

Lonowski. D. J.. \& Levitt. R. A. Inhibition of chemically elicited feeding and drinking by autonomic blocking agents. Behavioral Biology. 1973. 8. 251-259.

Lonowski. D. J., Levitt, R. A.. \& Larson. S. D. Mouse killing or carring by male and female Long-Evans hooded rats. Bulletin of the Psychonomic Society, 1973. 1. 349-351.

Moyer. K. E. Kinds of aggression and their physiological basis. Communications in Behavioral Biology. 1968, 2. 65-87.

Myer. J. S.. \& White. R. T. Aggressive motivation in the rat. Animal Behaviour. 1965. 13, 430433 .

Panksepp. J. Aggression elicited by electrical stimulation of the hypothalamus in albino rats. Phvsiologv \& Behavior. 1971.6. 321-329.

Smith. D. E.. King. M. B.. \& Hoebel, B. G. Lateral hypothalamic control of killing: Evidence for a cholinoceptive mechanism. Science. 1970. 167. 900-901.

(Received for publication May 17. 1973: revision received July 16.1973 .) 